\title{
Influence of hospital policy on partograph use in tertiary care facilities in India: a cross sectional survey
}

\author{
Shalini Singh" ${ }^{1 *}$, Vishwajeet Singh², Tushita Thakur', A. G. Radhika ${ }^{3}$, \\ Pratima Mittal $^{4}$, Jyotika A. Kashyap ${ }^{5}$, Abhilasha Gupta ${ }^{6}$, Neelam Aggarwal ${ }^{7}$
}

\begin{abstract}
${ }^{1}$ Department of Reproductive Biology and Maternal Health, Indian Council of Medical Research, New Delhi, India ${ }^{2}$ Department of Biostatistics, All India Institute of Medical Sciences, New Delhi, India

${ }^{3}$ Department of Obstetrics and Gynecology, GTB Hospital, Delhi, India

${ }^{4}$ Department of Obstetrics and Gynecology, VM Medical College and Safdarjung Hospital, New Delhi, India

${ }^{5}$ Department of Obstetrics and Gynecology, SSG Medical College and Hospital, Vadodara, Gujarat, India

${ }^{6}$ Department of Obstetrics and Gynecology, LLR Medical College and Hospital, Meerut, Uttar Pradesh, New Delhi, India

${ }^{7}$ Department of Obstetrics and Gynecology, Postgraduate Institute of Medical Education and Research, Chandigarh, India
\end{abstract}

Received: 12 August 2017

Accepted: 09 September 2017

*Correspondence:

Dr. Shalini Singh,

E-mail: shalinisingh.icmr@gmail.com

Copyright: (C) the author(s), publisher and licensee Medip Academy. This is an open-access article distributed under the terms of the Creative Commons Attribution Non-Commercial License, which permits unrestricted non-commercial use, distribution, and reproduction in any medium, provided the original work is properly cited.

\begin{abstract}
Background: Partograph is an effective, but underutilized tool for monitoring labour. This study examined the influence of hospital policy on the knowledge, attitude, practice and skills of doctors towards partograph plotting.

Methods: A cross-sectional survey among doctors posted in labour rooms of tertiary care public teaching hospitals of India was carried out, using self-administered questionnaire to assess knowledge, attitude and practice; and labour case scenarios were provided to assess partograph plotting skills. Chi-square test or Fisher's exact test were employed to test the significance of association between knowledge, attitude, practice and skills of 150 doctors working in hospitals with $(n=3)$ and without $(n=2)$ policy of routine partograph plotting.

Results: The majority of doctors in both groups had correct knowledge about different partograph components. However, doctors working in hospitals with a policy of partograph use, demonstrated significantly better skills using case scenarios for plotting partographs $(\mathrm{p}<0.01)$, and a positive attitude towards plotting partograph and its use as a decision support tool $(\mathrm{p}=0.000)$ as compared to doctors working in hospitals without a routine partograph plotting policy.

Conclusions: Hospital policy of routine partograph plotting may positively influence utilization of partograph in tertiary care public hospitals in India.
\end{abstract}

Keywords: Attitude, Hospital policy, Knowledge, Partograph, Practice

\section{INTRODUCTION}

The Government of India guidelines on skilled birth attendance recommend plotting partograph for all deliveries so that women with problems in labour can be identified early and referred to higher centres for appropriate care. ${ }^{1}$ Partograph use has also shown to increase frequency and regularity of monitoring and overall quality of care during labour. ${ }^{2}$ Despite this, the use of partogram is very low among healthcare providers in developing countries, including in India. ${ }^{3-6}$ Poor knowledge and skills in plotting partograph, shortage of 
staff, and non-availability of printed partograph sheets are commonly cited reasons for under-utilization of partograph. ${ }^{3,4,7}$ To the best of our knowledge, the influence of hospital policy on the knowledge, attitude and practice of doctors towards partograph plotting in tertiary care settings has not been reported. This pilot study was carried out to assess the differences in knowledge, attitude, practices and skills of doctors in hospitals with and without a policy of routine partograph plotting. This would help to identify measures needed to improve partograph utilization.

\section{METHODS}

This cross-sectional survey was conducted in JulyOctober 2014 among doctors posted in labour rooms of five tertiary care, public sector, teaching hospitals in India (Safdarjung Hospital, New Delhi; Guru Teg Bahadur Hospital, New Delhi; PGIMER, Chandigarh; Sir Sayajirao General Hospital, Vadodara; and LLR Medical College and Hospital, Meerut). The sites were purposively selected to include hospitals with a policy of routine partograph use $(n=3)$ and those which did not insist $(n=2)$ on routine partograph plotting. All new entrant doctors working in hospitals with a policy of routine partograph plotting were provided training in plotting partograph and faculty carried out frequent, random checks of labour case sheets for completion of partograph.

To carry out the survey, each participating hospital held a meeting of doctors posted in the labour room and explained the purpose of the study and invited them to participate in the study. Self-administered questionnaire containing pre-coded, multiple choice questions and a few open-ended questions to assess the knowledge, attitude and practice (KAP) of doctors regarding partograph use were provided for completion. Attitude of doctors towards partograph was based on their response of whether they considered it merely a duplication of work; and utilization in facilities was ascertained from questions on proportion of deliveries in which partograph was plotted and used as a tool for decision making.

To assess the competency of doctors in plotting partograph, three labour case scenarios (one with normal progress of labor and two with slow progress of labor with signs of fetal distress) were extracted from government guidelines (Government of India, 2010) and provided to the participants along with three blank simplified WHO partograph sheets for completion. Each case scenario mentioned patient identification details, clinical readings of cervical dilatation, duration and frequency of uterine contractions, pulse, blood pressure, temperature and fetal heart rate with time.

For scoring, each item was evaluated in all the three case scenarios. It was marked as 'correct', if the provider made correct entries in all the three case scenarios. A total of 15-20 minutes was given to complete the knowledge questionnaire and plot partograph for the labour case scenarios.

A scoring system was prepared for assessing knowledge and adequacy of completeness and correctness of the different parameters in the partograph. The completed KAP questionnaires and labour case scenarios were evaluated and scored by a trained researcher at each facility. Data from all sites was compiled at Indian Council of Medical Research, New Delhi for analysis. Analysis was done using Stata (V.11.2) and appropriate statistical tests were applied. The demographic profile of the doctors and suggestions to improve partograph for labour monitoring were analyzed as simple proportions and percentages.

Chi-square test or Fisher's exact test was employed to test the significance of association between knowledge, attitude, practice and skills of doctors working in hospitals with and without partograph plotting policy. Results are presented as proportion, percentages and association of hospitals with and without partograph policy. Descriptive and inferential principles were used to draw conclusions from the data.

\section{RESULTS}

A total of 150 doctors participated in the survey; of which $51.3 \%$ (77) were from hospitals with a policy of routine partograph plotting, and 48.7\% (73) were from facilities that did not insist on a policy of routine partograph plotting. The demographic details of the participants are summarized in Table 1 .

Table 1: Demographic profile of participants in hospitals with and without policy of partograph plotting.

\begin{tabular}{|lll|}
\hline $\begin{array}{l}\text { Demographic } \\
\text { characteristics }\end{array}$ & $\begin{array}{l}\text { Routine } \\
\text { plotting policy } \\
\text { N=77 }(\%)\end{array}$ & $\begin{array}{l}\text { Do not insist on } \\
\text { routine plotting } \\
\text { N=73(\%) }\end{array}$ \\
\hline Age & $4(05.2)$ & $11(15.1)$ \\
\hline$<25$ years & $63(81.8)$ & $62(84.9)$ \\
\hline 25-35 years & $10(13.0)$ & $0(00.0)$ \\
\hline$>35$ years & & \\
\hline Gender & $76(98.7)$ & $65(89.0)$ \\
\hline Female & $1(01.3)$ & $8(11.0)$ \\
\hline Male & & \\
\hline Cadre of doctors & $18(23.4)$ & $33(45.2)$ \\
\hline Interns & $34(44.1)$ & $9(12.3)$ \\
\hline Junior residents & $25(32.5)$ & $31(42.5)$ \\
\hline Specialists & & \\
\hline
\end{tabular}

Overall, during the last six months, $77.3 \%$ (116) participants reported receiving training in plotting partograph; however, 70\% (105) participants expressed the need for further training in plotting and interpreting findings of partograph, and there was no significant difference among doctors working in hospitals with or without a policy of partograph use (data not shown). 


\section{Knowledge, attitude and practice (KAP) of partograph}

Irrespective of the hospital policy on partograph plotting, nearly $60-76 \%$ doctors had correct knowledge about labour processes, and partograph (Table 2). Hospitals with a policy of routine partograph policy had a significantly higher $(\mathrm{p}=0.000)$ proportion of doctors with a positive attitude towards partograph plotting and they reported plotting partograph for more than $75 \%$ of deliveries.

Table 2: Knowledge, attitude and practice of partograph among participants in hospitals with and without policy of routine partograph plotting.

\begin{tabular}{|c|c|c|c|}
\hline $\begin{array}{l}\text { KAP } \\
\text { parameters }\end{array}$ & $\begin{array}{l}\text { Routine } \\
\text { plotting } \\
\text { policy } \\
\mathrm{N}=77(\%)\end{array}$ & $\begin{array}{l}\text { Do not insist } \\
\text { on routine } \\
\text { plotting } \\
\mathrm{N}=73(\%)\end{array}$ & $\begin{array}{l}\mathrm{p} \\
\text { value }\end{array}$ \\
\hline \multicolumn{4}{|c|}{$\begin{array}{l}\text { Correct knowledge of labour and partograph } \\
\text { components }\end{array}$} \\
\hline $\begin{array}{l}\text { Signs of onset of } \\
\text { labour }\end{array}$ & $72(93.5)$ & $66(90.4)$ & 0.485 \\
\hline $\begin{array}{l}\text { Cervical } \\
\text { dilatation when } \\
\text { plotting is begun }\end{array}$ & $70(90.9)$ & $60(82.3)$ & 0.116 \\
\hline $\begin{array}{l}\text { Rate of cervical } \\
\text { dilatation in } \\
\text { active labour }\end{array}$ & $65(84.4)$ & $61(83.6)$ & 0.887 \\
\hline $\begin{array}{l}\text { Normal foetal } \\
\text { heart rate }\end{array}$ & $76(98.7)$ & $73(100.0)$ & 1.000 \\
\hline $\begin{array}{l}\text { Significance of } \\
\text { labour curve } \\
\text { crossing the alert } \\
\text { line }\end{array}$ & $73(94.8)$ & $66(90.4)$ & 0.359 \\
\hline $\begin{array}{l}\text { Significance of } \\
\text { labour curve } \\
\text { crossing the } \\
\text { action line }\end{array}$ & $64(83.1)$ & $63(86.3)$ & 0.588 \\
\hline \multicolumn{4}{|c|}{ Attitude towards plotting } \\
\hline $\begin{array}{l}\text { Plotting } \\
\text { partograph is } \\
\text { duplication of } \\
\text { work }\end{array}$ & $0(0.0)$ & $14(19.2)$ & 0.000 \\
\hline \multicolumn{4}{|c|}{ Utilization of partograph } \\
\hline $\begin{array}{l}\text { Plotting in }>75 \% \\
\text { deliveries }\end{array}$ & $57(74.0)$ & $15(20.5)$ & 0.000 \\
\hline $\begin{array}{l}\text { Partograph used } \\
\text { in decision } \\
\text { making }\end{array}$ & $71(92.2)$ & $24(32.9)$ & 0.000 \\
\hline
\end{tabular}

\section{Competency in plotting Partograph}

The doctors fared poorly in completing patient identification data and delivery details for the three given case scenarios. Correct plotting of maternal and foetal condition, and progress of labour was significantly better $(\mathrm{p}<0.01)$ among participants from hospitals with a policy of routine partograph use as compared to those hospitals where partograph plotting was not a routine policy (Table $3)$.
Table 3: Competency of doctors in plotting partograph using case scenarios among participants in hospitals with and without policy of routine partograph plotting.

\begin{tabular}{|llll|}
\hline $\begin{array}{l}\text { Partograph } \\
\text { components } \\
\text { plotted correctly }\end{array}$ & $\begin{array}{l}\text { Routine } \\
\text { plotting } \\
\text { policy } \\
\mathbf{N}=77(\%)\end{array}$ & $\begin{array}{l}\text { Do not insist } \\
\text { on routine } \\
\text { plotting } \\
\mathbf{N}=73(\%)\end{array}$ & $\begin{array}{l}\text { p } \\
\text { value }\end{array}$ \\
\hline $\begin{array}{l}\text { Patient } \\
\text { identification data }\end{array}$ & $33(42.8)$ & $20(27.4)$ & 0.048 \\
\hline Maternal condition & $35(45.4)$ & $14(19.2)$ & 0.001 \\
\hline Foetal condition & & & \\
\hline $\begin{array}{l}\text { Foetal heart rate } \\
\text { Amniotic fluid } \\
\text { details }\end{array}$ & $38(75.3)$ & $19(26.0)$ & $<0.001$ \\
\hline $\begin{array}{l}\text { Labor progress } \\
\text { Cervical dilatation }\end{array}$ & $60(77.9)$ & $12(16.4)$ & $<0.001$ \\
\hline $\begin{array}{l}\text { Time on X axis } \\
\text { Uterine contractions }\end{array}$ & $15(19.5)$ & $21(28.8)$ & 0.015 \\
\hline Delivery details & $9(11.7)$ & 0 & 0.005 \\
\hline
\end{tabular}

The response rate for suggestions on how to improve utilization of partograph was 19.3 percent. Need for training and improving format of partograph were commonly expressed themes among other responses which are summarized in Table 4.

Table 4: Suggestions of participants for improving the use of partograph in labor monitoring.

\begin{tabular}{|c|c|}
\hline $\begin{array}{l}\text { Suggestions of participants (multiple } \\
\text { response) }\end{array}$ & $\begin{array}{l}\text { No. of } \\
\text { participants } \\
\mathrm{N}=29(\%)\end{array}$ \\
\hline Need training & $7(24.1)$ \\
\hline Simplify Partograph & $2(6.9)$ \\
\hline Improve Partograph format & \multirow{8}{*}{$14(48.3)$} \\
\hline Make it computerized & \\
\hline Make it colorful & \\
\hline $\begin{array}{l}\text { Include column for baby notes weight, } \\
\text { sex, APGAR score }\end{array}$ & \\
\hline $\begin{array}{l}\text { Include key high-risk factors of } \\
\text { pregnancy }\end{array}$ & \\
\hline Drug column is too small & \\
\hline Include latent phase of labor & \\
\hline $\begin{array}{l}\text { Include abdominal exam, effacement, } \\
\text { fetal descent, vaginal exam }\end{array}$ & \\
\hline Improvement in health systems & \multirow{3}{*}{$6(20.7)$} \\
\hline $\begin{array}{l}\text { Require hospital services improvement } \\
\text { to allow time for plotting }\end{array}$ & \\
\hline $\begin{array}{l}\text { Availability of paper forms should be } \\
\text { ensured }\end{array}$ & \\
\hline $\begin{array}{l}\text { Change negative attitude of providers } \\
\text { towards plotting partograph }\end{array}$ & $3(10.3)$ \\
\hline
\end{tabular}

\section{DISCUSSION}

Freidman prepared a cervicograph in 1954 after studying pattern of cervical dilatation during labor. Philpott used this along with some key maternal and fetal parameters to monitor progress of labour. Over the years, the WHO has 
modified the designs of the partograph, based on the utility of the different components of partograph and ease of recording, but without compromising the benefits of partograph. The currently recommended 'simplified' WHO partograph especially caters to the needs of peripheral health workers; it is color coded and plotting is initiated at $4 \mathrm{~cm}$ cervical dilatation and excludes plotting descent of the presenting part. ${ }^{8}$

This 'simplified' WHO partograph has been included in the guidelines for skilled birth attendance (Government of India, 2010) in India since the year 2005, for monitoring progress of labor. Pre-service and in-service trainings of providers include training in partograph plotting. Despite this, poor utilization of partograph $(6 \%)$ with retrospective plotting was reported in a survey of 73 facilities in three districts of Madhya Pradesh, India. The study concluded that creating a policy to promote routine use of the partograph is not enough to ensure its implementation in the programme; and issues of work overload, staff shortages, training and supervision should also be addressed to promote partograph use ${ }^{6}$.

Considering that tertiary level, teaching hospitals have a better environment for supportive supervision; we examined the knowledge, skills and attitude of doctors towards partograph use in tertiary care teaching hospitals with and without a policy of partograph use.

Overall, the participating doctors had a fair knowledge about assessment of labor using partograph. However, doctors in public hospitals with a policy of routine partograph use had better competency in plotting partograph using case scenarios $(\mathrm{p}<0.01)$; a positive attitude towards plotting partograph and reported better utilization of partograph during deliveries as compared to doctors in hospitals where partograph plotting was not insisted upon routinely.

Present results also indicate that even though majority doctors reported to have attended at least one training session in the last six months, doctors in both the groups felt the need for further training in use and interpretation of partograph. This indicates a need to devise better training programmes or self-learning tools for providers which will enhance their competency levels and help them to use partograph as a decision supporting tool. Education on how to use partogram has been shown to enhance quality of care offered by midwives and improves recording of maternal and fetal parameters in labour in a study from Iran. ${ }^{2}$ The positive attitude of doctors in the present study towards plotting partograph in hospitals with a policy of plotting partograph can be harnessed to improve perinatal outcomes, as has been reported in a demonstration project carried out in 13 maternity hospitals of Russia. ${ }^{9}$

Present findings support the conclusion of a systematic review which assessed the barriers to and incentives for partograph use in low and middle-income countries, and reported that professional skills, practice of providers, as well as the organizational environment including clinical leadership and quality assurance practiced at the facility, influence the utilization of partograph. ${ }^{10}$

The providers in present study suggested a need for improving and simplifying partograph format; better staffing and availability of printed forms and change in negative attitude of providers to improve the utilization of partograph for labor monitoring. This is a pilot study with a small sample size; however, it indicates that doctors working in hospitals with a policy of routine partograph plotting had better competence, improved utilization and positive attitude towards plotting partograph. Therefore, introduction of a routine partograph plotting policy and regular trainings may improve utilization of partograph in public hospitals in India.

\section{CONCLUSION}

Hospital policy of routine partograph plotting may positively influence utilization of partograph in tertiary care public hospitals in India.

\section{ACKNOWLEDGMENTS}

The authors would like to thank all the study participants.

Funding: No funding sources

Conflict of interest: None declared

Ethical approval: The study was approved by the Institutional Ethics Committee

\section{REFERENCES}

1. Government of India: Guidelines for antenatal care and skilled attendance at birth by ANMs/LHVs/SNs. Government of India: Maternal Health Division, Ministry of Health and Family Welfare; 2010.

2. Modares M, Mirmolaee ST, Miromohammadalie M, Valizadeh MA, Ziyaee M, Hashemi FA. The effects of education on the use of partogram to control the quality of care offered by midwives. Res J Biol Sci. 2009;4(2):152-6.

3. Yisma E, Dessalegn B, Astaktie A, Fesseha N. Knowledge and utilization of partograph among obstetric care givers in public health institutions of Addis Ababa, Ethiopia. BMC Pregnancy Childbirth 2013;13:17

4. Abebe F, Birhanu D, Awoke W, Ejigu T. Assessment of knowledge and utilization of the partograph among health professionals in Amhara region, Ethiopia. Sci J Clin Med. 2013;2:26-42.

5. Spector JM, Agarwal P, Kodkany B, Lipsitz S, Lashoher A, Dziekan G, et al. Improving quality of care for maternal and newborn health: prospective pilot study of the WHO safe childbirth checklist program. PLoS One. 2012;7:e35151.

6. Chaturvedi S, Upadhyay S, De Costa A, Raven J. Implementation of the partograph in India's JSY 
cash transfer programme for facility births: a mixed methods study in Madhya Pradesh province. BMJ Open. 2015;5:e006211.

7. Kushwah B, Singh AK, Singh S. The Partograph: an underutilized tool. J Evol Med Dental Sci. 2013;2(24):4373-9.

8. Mathai M. The partograph for the prevention of obstructed labor. Clin Obstet Gynecol. 2009;52(2):256-69.

9. United States Agency International Develeopment (USAID). Improving care for mothers and babies: In the Russian federation collaborative on optimizing labor management through use of the partograph. Available at https://www.usaidassist.org/sites/assist/files/partogra ph-report.pdf Accessed on 4th July 2016.
10. Ollerhead E, Osrin D. Barriers to and incentives for achieving partograph use in obstetric practice in lowand middle-income countries: a systematic review. BMC pregnancy and childbirth. 2014;14(1):281.

Cite this article as: Singh $\mathrm{S}$, Singh V, Thakur T, Radhika AG, Mittal P, Kashyap JA, Gupta A, Aggarwal N. Influence of hospital policy on partograph use in tertiary care facilities in India: a cross sectional survey. Int $\mathbf{J}$ Reprod Contracept Obstet Gynecol. 2017;6:4890-4. 